\title{
Duble uma teoria: a dublagem como dispositivo educomunicativo no ensino de teorias da comunicação
}

\section{Rafael Grohmann}

Professor do Mestrado e Doutorado em Comunicação da Universidade do Vale do Rio dos Sinos (Unisinos).

E-mail: rafaelgrohmann@unisinos.br

Resumo: $\mathrm{O}$ artigo discute dublagens como dispositivos educomunicativos no ensino de teorias da comunicação, considerando possibilidades, limites e brechas. A partir de experiências pedagógicas em sala de aula na graduação, o texto procura compreender questões de práxis, circulação de sentidos, remix e a própria comunicação/ circulação das Teorias da Comunicação para além do campo acadêmico, em um movimento entre "epistemologizar a cultura pop" e "popularizar a epistemologia".

Palavras-chave: circulação de sentidos; dispositivo educomunicativo; dublagem; epistemologia; teorias da comunicação.
Abstract: This article discusses dubbing as a dispositif in communication theory education, considering possibilities, limits and gaps. Based on pedagogical experiences in the classroom in undergraduate courses, this paper aims to understand questions of praxis, circulation of meanings, remix and the very communication/circulation of communication theories beyond the academic field, in a movement between "epistemologizing pop culture" and "popularizing epistemology".

Keywords: circulation of meanings; dispositif/dubbing; communication theory; epistemology. 


\section{INTRODUÇÃO}

Na última década, o campo da comunicação no Brasil se solidificou tanto institucionalmente - como evidencia, por exemplo, o exponencial crescimento dos programas de pós-graduação - quanto em termos de discussões epistemológicas, também concretizadas em congressos, periódicos e livros da área. Contudo, se a dimensão epistemológica apresenta uma posição de destaque no campo, parece haver, como aponta $\mathrm{Martino}^{1}$, uma assimetria em relação aos debates sobre o cotidiano envolvendo a concretização desses debates na sala de aula, principalmente na graduação.

A dimensão do ensino de teorias da comunicação ${ }^{2}$ tem sido um ponto cego nos artigos da área. Uma exceção é o texto de Russi-Duarte ${ }^{3}$. Para o autor, a sala de aula deve ser encarada como um laboratório cotidiano. Sua preocupação se mostra alinhada às nossas indagações: como convertemos nossas discussões epistemológicas em experiências concretas pedagógicas, desde a escolha da bibliografia até os métodos de avaliação? Como avaliar, pois, no ensino de teorias da comunicação?

O presente artigo nasce da reivindicação de um espaço de debate mais amplo para o "chão de fábrica" das teorias da comunicação: os processos pedagógicos, de ensino-aprendizagem, de um modo a procurar não fechar a ciência em si mesma, tal qual uma "razão escolástica", trazendo para congressos e revistas mais relatos e compartilhamento de experiências. Um outro exemplo é o de Ferraz ${ }^{5}$, que apresenta a modelização/modelagem como recurso didático em Teorias da Comunicação a partir de experiência na Universidade Federal de Juiz de Fora (UFJF). Neste artigo, discutimos especificamente o dispositivo de "dublagem" como recurso possível no ensino de teorias da comunicação, a partir de experiências entre 2012 e 2018 como docente da disciplina - isto é, não se trata de um estudo de recepção com estudantes sobre teorias da comunicação. A partir de uma reflexividade epistemológica da prática docente, o artigo busca refletir sobre outros modos de fazer circular as teorias da comunicação em um duplo movimento: popularizar a epistemologia e epistemologizar a cultura pop. Então, refletimos sobre as possibilidades e os limites da dublagem como dispositivo educomunicativo.

\section{COMUNICAR AS TEORIAS?}

Antes de focar propriamente em práticas pedagógicas em teorias da comunicação, é preciso esclarecer o que se entende por ciência. $\mathrm{O}$ olhar para a praxis nos permite compreender a ciência e a pesquisa científica a partir da concretude e da materialidade da vida social, de maneira que uma ciência ensimesmada - ou uma "epistemologia pela epistemologia”, de certa forma, estéril - pode não contribuir para a produção de conhecimento em sociedade. Conforme Álvaro Vieira Pinto ${ }^{6}$, "não devemos cair na concepção ingênua da epistemologia sem sujeito, da metodologia sem o homem”, pois a prática da pesquisa é, antes de tudo, uma prática social.

Do contrário, recai no que Bourdieu ${ }^{7}$ chama de "etnocentrismo escolástico", que seria uma "illusio acadêmica", de forma próxima ao que seria nomeado
1 MARTINO, Luís Mauro Sá A disciplinarização da Epistemologia no ensino da (s) Teoria (s) da Comunicação. Intexto, Porto Alegre, n. 29, p. 1-17, 2013.

2. Compreendemos aqui "teorias da comunicação" não somente como a disciplina homônima, mas o conjunto de disciplinas na graduação que se dedicam a compreender dimensões teórico-epistemológicas da comunicação.

3. RUSSI-DUARTE, Pedro. Por que ensinar teoria (da comunicação)?. In: INTERCOM, 10., 2010, Caxias do Sul. Anais [...]. Caxias do Sul: UCS, 2010.

4. BOURDIEU, Pierre. Meditações pascalianas. Rio de Janeiro: Bertrand Brasil, 2001.

5. FERRAZ, Luiz Marcelo Robalinho. A modelização como ferramenta complementar no ensino de Teoria da Comunicação. Comunicação \& Educação, São Paulo, v. 23, n. 1, 2018.

6. VIEIRA PINTO, Álvaro. Ciência e existência: problemas filosóficos da pesquisa científica. Rio de Janeiro: Paz e Terra, 1979. p. 491. 
atualmente como "academicismo": esse processo, segundo o autor, "leva a anular a especificidade da lógica prática, quer assimilando-a à lógica escolástica, embora de maneira fictícia e puramente teórica (vale dizer, no papel e sem consequências práticas), quer remetendo-a à alteridade radical, à não-existência”. Neste sentido, podemos dizer que não é possível compreender prática sem teoria, nem o contrário, entrelaçadas que são, como se rebatesse um eco vindo das salas de aula: "para que serve a teoria?". Segundo Vieira Pinto ${ }^{8}$, "como o pensamento teórico, o mundo das ideias, a reflexão abstrata, não existe jamais separado do plano objetivo, e portanto, desligado da prática. Não há trabalho nem ação prática sobre o mundo material que não dê em resultado de novas ideias”. É, pois, nesse vai-e-vem entre teoria e prática, ou na práxis dos sujeitos sociais, que, simultaneamente, pensam e atuam sobre a realidade que podemos pensar o contexto de ensino-aprendizagem em teorias da comunicação.

Junto a essa perspectiva sobre práxis e ciência, partimos da premissa, em conformidade com Freire $^{9}$, de que não existe processo educacional que não envolva processo comunicacional. Tanto um quanto outro são pautados pelo diálogo, o que não significa desconsiderar as relações de poder ou os conflitos, que são, pois, também constitutivos dos processos. Nas práxis dos sujeitos envolvidos no ensino-aprendizagem (enquanto algo, portanto, dialógico e não linear) em teorias da comunicação, não há só "ensino" ou "aprendizagem”, mas também a comunicação das teorias. Desde o desenho do programa, passando pela seleção dos textos-base, até as relações desenvolvidas em sala de aula e os métodos de avaliação: tudo envolve, portanto, modos de comunicar as teorias. Quais visões teórico-epistemológicas de comunicação e de educação estão ali implicadas?

Nesse cenário estão em jogo - aprender/comunicar/ensinar Teorias da Comunicação -a produção e a circulação de sentidos. Na busca pela "significação do significado"10, sentidos são produzidos, construídos e entram em disputa. Sobre os conceitos e autores apreendidos (ou não) e ressignificados. Acerca da própria visão em relação à disciplina - e como isso se liga, na visão dos estudantes, à graduação cursada. Sentidos de teorias da comunicação e pesquisa em comunicação. Significados estes que, por sua vez, não são formados somente na disciplina ou mesmo em sala de aula, mas circulam nos diferentes meios, instituições e interações (de forma midiatizada ou não).

A circulação de sentidos, enquanto um processo dialético, é como uma tradu-

7. BOURDIEU, Pierre. op. cit., 2001. p. 63 .

8. VIEIRA PINTO, Álvaro. op cit., 1979. p. 45.

9. FREIRE, Paulo. Extensão ou comunicação? Rio de Janeiro: Paz e Terra, 1985.

10. Ibidem

11. SILVERSTONE, Roger. Por que estudar a mídia? São Paulo: Loyola, 2002 p. 35 . ção, que "nunca é completa, sempre transformativa, e nunca, talvez, inteiramente, satisfatória"11, algo que envolve confiança e agressão em relação à produção de significados. Como, portanto, são produzidos e circulado os sentidos acerca de teorias da comunicação nos mais diversos lugares? Ou: como podemos fazer circular, comunicar e "traduzir" as teorias para além do circuito acadêmico já estabelecido (que envolve a leitura de livros e periódicos especializados e ida a congressos)?

Essa circulação em relação às teorias da comunicação passa pelo contexto de transformações da comunicação científica e do próprio trabalho acadêmico e suas relações com as mídias digitais. Trata-se de 
uma reconfiguração da comunicação científica como parte do trabalho acadêmico pela popularização das tecnologias de comunicação que propiciaram uma nova ordem de engajamento dos atores científicos, midiatizando a visibilidade científica através das mídias sociais ${ }^{12}$.

Isso não acontece somente com a produção acadêmica dos pesquisadores, mas com todo o processo pedagógico-comunicacional nas instâncias acadêmicas. Essas reconfigurações, de alguma maneira, podem ajudar a tensionar a "razão escolástica" no sentido de um "comunicar as Teorias" para além do próprio campo acadêmico da comunicação. Uma maneira de fazer comunicar e circular as Teorias é a partir dos trabalhos desenvolvidos pelos estudantes na disciplina entendidos como espaços para aprendizagem e visibilidade. Exercícios para tradução e "edição de mundo" a partir dos conceitos das teorias da comunicação: "editar é, portanto, construir uma realidade outra, a partir de supressões ou acréscimos em um acontecimento. [...] Editar é reconfigurar alguma coisa, dando-lhe novo significado"13. Trata-se, portanto, da circulação de significados de teorias da comunicação envolvendo processos comunicacionais e educacionais, inter-relacionando teoria e prática.

Neste sentido, colocamos o termo "dispositivo educomunicativo" para pensar experiências pedagógicas e comunicacionais que envolvam circulação das teorias da comunicação. A ideia relacionada ao termo não é nova, visto a própria trajetória da educomunicação no país ${ }^{14}$. Martini ${ }^{15}$ chega a falar em "dispositivo de educomunicação", mas para se referir a um website educomunicativo, não sendo, neste caso, inserido nos processos pedagógicos formais.

Partimos de uma noção restrita de dispositivo, entendido como "dispositivo comunicacional", a partir de Maingueneau ${ }^{16}$. Para ele, o dispositivo comunicacional é menos abrangente que o dispositivo foucaultiano e mais do que mero suporte ou ferramenta. Trata-se de um "conjunto do circuito que organiza a fala" envolvendo suportes materiais de produção e situações de difusão e recepção, ou seja, de comunicação. A concepção de dispositivo em Peraya é próxima e compreendida como um "lugar social de interação e de cooperação com intenções, funcionamento e modos de interação próprios" ${ }^{\text {"18 }}$. Isto é, não se trata de algo instrumental, mas que há possibilidades de (re)apropriações e ressignificações.

O que chamamos aqui de "dispositivo educomunicativo" ${ }^{19}$ é, então, um tipo de dispositivo comunicacional em que se alinham processos educativos e comunicacionais no sentido de aperfeiçoar questões comunicacionais "das ações educativas, incluindo as relacionadas ao uso de recursos da informação no processo de aprendizagem" ${ }^{20}$. A produção de dispositivos educomunicativos pretende, portanto, fazer circular e comunicar os conceitos desenvolvidos nas disciplinas nas mais diferentes plataformas. Em nosso caso: como fazer com que pessoas de fora do campo acadêmico se interessem por e aprendam teorias da comunicação?

Isso significa pensar as interrelações entre linguagem, cultura midiática (pop) e educação, com determinados modos de educar e comunicar, conforme apontam há algum tempo literatura consolidada sobre comunicação e educação ${ }^{21}$. Dispositivos educomunicativos - como jogos e vídeos - apresentam
12. OLIVEIRA, Thaiane. Midiatização da ciência: reconfiguração do paradigma da comunicação científica e do trabalho acadêmico na era digital. MATRIZes, São Paulo, v. 12, n. 3, p. 103, 2018

13. BACCEGA, Maria Aparecida. Do mundo editado à construção do mundo. Comunicação \& Educação, São Paulo, v. 1, n. 1, p. 8, 1994

14. CITELLI, Adilson; COS TA, Cristina (org.). Educomunicação: construindo uma nova área de conhecimento. São Paulo: Paulinas, 2011

15. MARTINI, Rafael. Educação e comunicação em ambiente associativo: web site como um dispositivo de educomunicação. 2009. Dissertação (Mestrado em Educação) - Universidade do Estado de Santa Catarina, 2009.

16. MAINGUENEAU, Dominique. Análise de textos de comunicação. São Paulo: Cortez, 2001.

17. Ibidem. p. 72.

18. PERAYA, Daniel. O ciberespaço: um dispositivo de comunicação e de formação midiatizada. In: ALAVA, Séraphin (org.). Ciberespaço e formações abertas: rumo a novas práticas educacionais? Porto Alegre: Artmed, 2002. p. 25-52.

19. Não é nossa intenção, aqui, se debruçar sobre a extensa bibliografia sobre comunicação e educação, mas tão-somente elucidar nosso ponto de vista para apreensão do objeto em questão

20. SOARES, Ismar de Oliveira. Gestão comunicativa e educação: caminhos da educomunicação. Comunicação \& Educação, São Paulo, n. 23, p. 24, 2002. 
21. Conferir, por exemplo: CITELLI, Adilson. Comunicação e educação: a linguagem em movimento. São Paulo: Ed. Senac, 2000.; FISCHER, Rosa Maria Bueno. O dispositivo pedagógico da mídia: modos de educar na (e pela) TV. Educação e Pesquisa, São Paulo, v. 28, n. 1, p. 151-162 2002; Não é nossa intenção discutir tal bibliografia neste artigo, pois consideramos que a própria revista Comunicação \& Educação já apresenta material rico suficiente a respeito dessas interrelações

22. WOODCOCK, Jamie. Marx at the arcade: consoles, controllers, and class struggle. London: Haymarket, 2019.

23. SILVERSTONE, Roger. op. cit., 2002.

24. KELLNER, Douglas; KIM, Gooyong. YouTube, critical pedagogy, and media activism. The Review of Education, Pedagogy, and Cultural Studies, Abingdon, v. 32, n. 1, p. 3-36, 2010 gramaticalidades próprias da cultura midiática ao mesmo tempo em que apresentam políticas $^{22}$ e, ao mesmo tempo, possibilitam reapropriações e outras circulações de sentidos na ordem de remixagem e consumo, como apontam autores como Silverstone ${ }^{23}$ e Kellner ${ }^{24}$.

Desta forma, a crítica midiática - nos planos do conteúdo e da expressão ${ }^{25}$ são necessárias como parte do movimento de "epistemologizar a cultura pop". Compreender as gramaticalidades dos dispositivos comunicacionais como políticas significa, pois, perceber como formatos, especificidades e lógicas de plataformas moldam a produção e a circulação dos dispositivos comunicacionais. Não existe fala ou escrita que não seja escrita em um meio. Assim, os dispositivos comunicacionais que se inscrevem no Youtube ou no Instagram também têm suas características próprias a partir das materialidades midiáticas.

Em nossa trajetória como docente, entre outros dispositivos educomunicativos, foram produzidos pelos estudantes jogos de tabuleiro e cards de RPG com o intuito de introduzir, por meio dos jogos, conceitos e autores vistos ao longo da disciplina, conforme pode ser visto na Figura 1.

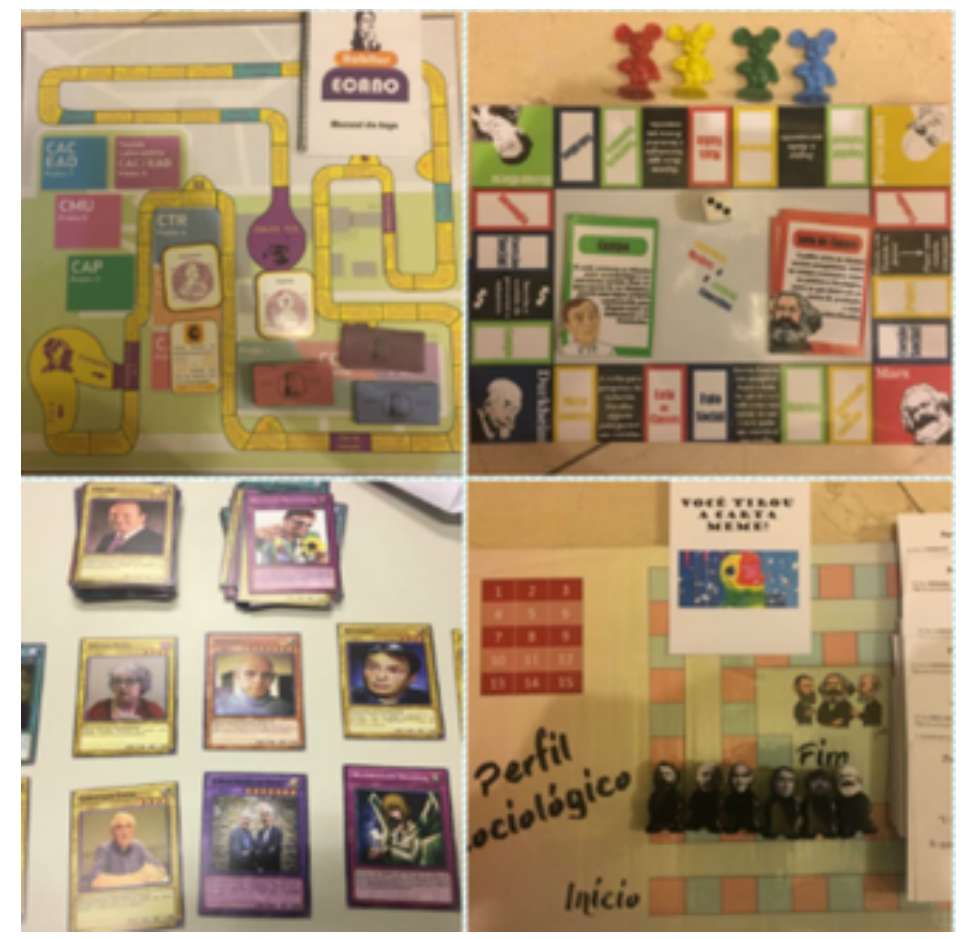

Figura 1: Exemplos de dispositivos educomunicativos

Fonte: Elaborado pelo autor.

Há uma aprendizagem educomunicativa, em primeiro lugar, por parte dos estudantes, que precisam pensar em maneiras de melhor comunicar os conceitos e autores - isto é, uma reflexão acerca dos próprios processos comunicacionais e, ao mesmo tempo, fazer com que esses dispositivos auxiliem na aprendizagem. É, portanto, uma aprendizagem por meio do lúdico e do entretenimento. Mas os 
dispositivos educomunicativos não se pretendem - e nem poderiam ser - substitutos de livros ou textos, pois são dispositivos comunicacionais diferentes, a partir de ordens outras de produção e consumo. Desta forma, não se pretende que o consumidor desses dispositivos se torne um expert em Habermas, McLuhan ou Martín-Barbero, tratando-se mais de uma introdução aos conceitos. Este é o contexto em que se situa a proposta de dublagens como dispositivos educomunicativos.

\section{A EPISTEMOLOGIA É POP: A DUBLAGEM COMO DISPOSITIVO}

Imagine um vídeo em que Chaves e o Professor Girafales explicam as mediações de Martín-Barbero. Ou um em que Paola Bracho, da novela "A Usurpadora" apresente a noção de "sociedade do controle" em Deleuze. O que chamamos aqui por "dublagens" são vídeos - cenas de filmes, desenhos, séries, novelas e videoclipes - em que o áudio original é retirado e uma dublagem é realizada a fim de explicar conceitos vistos na disciplina. Uma montagem ou uma bricolagem em um produto audiovisual veiculado nas plataformas digitais no sentido de "editar" um mundo de conceitos das teorias da comunicação.

Trata-se de um entrelaçamento entre a cultura midiática - especialmente cultura audiovisual e cultura pop - e as teorias da comunicação. As memórias advindas desta cultura das mídias auxiliam no processo de identificação com o dispositivo de dublagem: a cena favorita da telenovela, o videoclipe da música que ficou entre as mais ouvidas, o diálogo mais famoso do filme que ganhou o Oscar. Se o dispositivo fosse trocado por um curta-metragem ou um vídeo estilo youtuber, com as mesmas explicações dos conceitos, o resultado seria outro.

O que está em cena nas dublagens são ressignificações próprias de uma "cultura do remix" que não é nova em relação às atividades culturais humanas (gastronomia ou música, por exemplo), mas se intensifica com as facilidades de produção e compartilhamento de conteúdo em ambiências digitais, isto é, a circulação dos conteúdos remixados em contexto de plataformas digitais. O remix para circular. Esta remixagem significa, segundo Lemos ${ }^{26}$ um "conjunto de práticas sociais e comunicacionais de combinações, colagens, cut-up de informação a partir das tecnologias digitais". A partir desse processo, algo novo é construído.

Enquanto remix, a linguagem das dublagens necessita do "original" a ser remixado, não somente as imagens do vídeo, mas com construções de vínculos em relação ao material original. A partir das categorizações de remix propostas por Navas $^{27}$ em "estendido", "seletivo" e "reflexivo", podemos considerar as dublagens como remixes reflexivos à medida que "subverte o texto-fonte ao mesmo tempo em que explicita as referências a ele" ${ }^{28}$, a partir de uma só fonte para remixagem.

Outra característica das dublagens, enquanto dispositivos comunicacionais/ educomunicativos, é a presença de elementos intertextuais e paratextuais. Se a interdiscursividade é constitutiva dos discursos, a intertextualidade se mostra nas relações discursivas materializadas em texto. Uma interdiscursividade mostrada
25. HJELMSLEV, Louis. Prolegômenos a uma teoria da linguagem. São Paulo: Perspectiva, 1975.

26. LEMOS, André. Ciber-cultura-remix. Apresentação proferida na mesa "Redes: criação e reconfiguração", do Seminário "Sentidos e Processos". São Paulo: Itaú Cultural, 2005, p. 5.

27. NAVAS, Eduardo Regressive and reflexive mashups in sampling culture. In: SONVILLA-WEISS, Stefan (org.). Mashup cultures. New York: Springer, 2010. p. 157-177. 
28. BUZATO, Marcelo. et al. Remix, mashup, paródia e companhia: por uma taxonomia multidimensional da transtextualidade na cultura digital. Revista Brasileira de Linguística Aplicada Belo Horizonte, v. 13, n. 4, p. 1203, 2013

29. GENETTE, Gérard. Seuls. Paris: Éditions du Seuil, 1987.

30. DALMONTE, Edson. Novos cenários comunicacionais no contexto das mídias interativas: o espaIhamento midiático. Famecos, Porto Alegre, v. 2, n. 17, p. 105, 2015.

31. SILVERSTONE, Roger. op. cit., 2002.

32. Ibidem. p. 33.

33. MARTIN-BARBERO, Jesús. Dos meios às mediações. Rio de Janeiro: Ed. UFRJ, 1995. e marcada, mesmo implicitamente. São as relações intertextuais que ajudam a marcar os vínculos do remix com a obra original, tanto imageticamente quanto por parte do texto "novo".

Já os paratextos, estudados por Genette ${ }^{29}$ como prolongamentos ou continuidades de obras, não se perdem com as produções em ambiências digitais. Como mostra Dalmonte ${ }^{30}$,

os elementos que constituem o paratexto são oriundos de um conjunto marcado pela diversidade de práticas e discursos, que confluem para a formação do sentido da obra num contexto mais amplo. A noção de atualização envolvendo a obra resulta de uma movimentação social em torno de um produto que, não obstante traga as marcas que lhe foram agregadas no processo de feitura, está aberta a receber outras "inscrições", como resultado da apropriação social.

Essa atualização pela transformação do texto "original" resulta em uma reapropriação e uma recirculação dessas obras, produzindo, pois, novos sentidos às narrativas já estabelecidas - e inclusive, tensionando os antigos significados. Para Silverstone ${ }^{31}$, ocorre um constante movimento dos significados "à medida que textos da mídia e textos sobre a mídia circulam em forma escrita, oral e audiovisual, e à medida que nós, individual e coletivamente, direta e indiretamente, colaboramos para sua produção" ${ }^{32}$.

Assim, com elementos intertextuais e paratextuais, as dublagens circulam nos mais diferentes meios a partir da montagem/recombinação de vídeos advindos das indústrias midiáticas ou mesmo das produções já provenientes da cultura digital, com o conteúdo de autores de teorias da comunicação. Podemos conceber essas produções a partir das brechas, conforme Martín-Barbero ${ }^{33}$, enquanto lugares de ressignificações e reapropriações do massivo. As brechas são o que permitem, ao mesmo tempo, o reconhecimento e a aprendizagem por parte de quem assiste às dublagens. Um movimento dialético entre "epistemologizar a cultura pop" e "popularizar a epistemologia".

Entender as dublagens como dispositivos educomunicativos passa por justamente compreender as potências e limites dessas brechas nesse movimento entre teorias da comunicação e cultura pop. Poder-se-ia dizer, em uma perspectiva, que explicar Adorno em um vídeo do desenho Toy Story ou Foucault no clipe das Spice Girls é ser "colonizado" pelos enquadramentos próprios da "indústria cultural”, espetacularizando a teoria e excluindo qualquer possibilidade de emancipação "por dentro" do sistema. Se, por um lado, nos afastamos desse ponto-de-vista, por outro, não podemos recair em um movimento contrário: o de que esses dispositivos seriam "revolucionários" ou "resistências à hegemonia".

Há de se considerar os constrangimentos e as limitações das próprias materialidades midiáticas dos dispositivos educomunicativos enquanto remix, ou seja, as imagens já estão dadas e os espaços no roteiro para as falas já estão pré-determinados de acordo com o vídeo original. As limitações também envolvem o próprio processo educacional-comunicacional em que nem sempre o movimento de epistemologizar a cultura pop se dá de forma crítica em relação 
aos dispositivos midiáticos pré-existentes. As discussões sobre cenas e roteiros se dão ao longo das aulas, em movimentos e tentativas de reapropriação de sentidos. O próprio momento de apresentação dos trabalhos é marcado pela crítica midiática aos conteúdos produzidos - e circulados.

Outra questão limitadora se refere aos direitos autorais dos vídeos originais pertencentes, em geral, aos grandes conglomerados midiáticos. Às vezes, as empresas bloqueiam os vídeos de dublagens por causa dos direitos autores, mesmo quando se afirma que as intenções do projeto são educacionais e sem fins lucrativos. Por um lado, então, a questão dos direitos autorais pode ser interpretada como uma forma de "piratear", "burlar" ou "contrabandear" o sistema; por outro, os vídeos ficariam à mercê de protocolos e vontades das indústrias midiáticas.

Entre a total reprodução do sistema e a mudança completa, as dublagens atuariam, portanto, como tentativas - gostaria de reforçar o acento em "tentativas" pedagógicas e comunicacionais - de fissuras, atuando nas frestas dos sentidos previamente atribuídos. Atuar nas brechas, no caso desses dispositivos educomunicativos, significa a possibilidade de aprendizagem/letramento em Teorias da Comunicação a partir da produção de sentido do remix. Nesse sentido, há o movimento de "epistemologizar a cultura pop", compreendendo a cultura pop e o entretenimento como lugares também passíveis de questionamentos e, por que não, de atividades epistemológicas e políticas ${ }^{34}$.

O movimento de "popularizar a epistemologia", no caso desses dispositivos, envolve, por um lado, como já afirmado, a amplificação da circulação das teorias para além de espaços demarcadamente acadêmicos. Por outro, a própria linguagem contida no dispositivo pode dar a ver certo tom de profanação dos autores e suas respectivas obras. Como se sentiria, pois, Dominique Wolton ao ver seus conceitos sendo explicados pela personagem Nazaré, da novela "Senhora do Destino"? Podemos dizer, de certa maneira, que Marshall McLuhan já experimentou tal profanação ao ser personagem de si mesmo em cena do filme "Noivo Neurótico, Noiva Nervosa" (Annie Hall), de Woody Allen. No caso das dublagens, trata-se menos de ridicularizar as figuras acadêmicas do que procurar tensionar a "razão escolástica".

A partir desses movimentos, marcamos os vídeos de dublagens de teorias da comunicação como uma possibilidade, no campo mesmo dos possíveis e das tentativas do "chão de fábrica" do ensino da disciplina na graduação. Após a problematização da dublagem enquanto um dispositivo educomunicativo, relatamos, a seguir, o percurso nosso em relação ao projeto, com o intuito de compartilhamento de experiências.

\section{DUBLANDO AS TEORIAS}

Desde 2012 até 2018, foram produzidos mais de 100 vídeos de dublagens por estudantes de graduação nas disciplinas ministradas. Entretanto, a primeira experiência com um vídeo de dublagem de teorias da comunicação - de onde

34. STREET, John. Politics and popular culture. London: Temple, 1997. 
surgiu a ideia para a prática pedagógica - se deu ao assistir ao vídeo "Lazarsfeld apanha de Adorno", um trabalho realizado por estudantes da Universidade Federal Fluminense (UFF), orientado pela professora Ana Lúcia Enne. O vídeo apresentava uma cena da novela "Celebridade", exibida pela Rede Globo em 2003, em que as personagens das atrizes Malu Mader e Cláudia Abreu eram, na dublagem, respectivamente, Theodor Adorno e Paul Lazarsfeld, que se duelavam ao explicar alguns parâmetros da "teoria crítica" e da "teoria funcionalista". A dublagem apresenta, em 10 de julho de 2018, 17.604 visualizações no Youtube.

Meses após a assistência do vídeo, resolvi transformar em prática pedagógica recorrente o exercício de tais vídeos de dublagens por parte dos estudantes. A ideia geral era que cada grupo de alunos estudasse a fundo um texto-base visto ao longo do período e transformasse seu conteúdo em um vídeo de dublagem, de modo que, ao fim do semestre - período em que, em algumas universidades, há a obrigação de uma "Semana de Provas" - todos os conceitos e autores debatidos na disciplina estivessem representados nas dublagens. Desta forma, se todos os trabalhos contivessem os conteúdos bem explicados, todos os estudantes poderiam estudar para as avaliações finais também a partir dos vídeos.

Ou seja, por um lado, os estudantes atuam como produtores de conteúdo mediadores no sentido de Silverstone ${ }^{35}$, tradutores transformando um texto da bibliografia da disciplina em um vídeo de cinco minutos, com os constrangimentos próprios do dispositivo (como mostramos anteriormente). Nesse processo simultâneo de comunicação e educação, fazem circular significados de um texto (bibliografia) para outro (vídeo de dublagem), "editando" e construindo determinado mundo das teorias da comunicação (ou determinados regimes de visibilidades para as teorias). Por outro lado, os mesmos estudantes são receptores-consumidores dos vídeos de dublagens dos colegas, aprendendo sobre outros conceitos e teorias. Um circuito de produção e consumo, envolvendo processos comunicacionais e educacionais em ambas as esferas: aprendizado ao produzir e ao consumir as dublagens, em uma circulação da aprendizagem teórica em comunicação. Outra dimensão da aprendizagem e da dublagem como um dispositivo educomunicativo é o uso posterior dos vídeos em sala de aula pelo professor, mostrando às outras turmas o que estudantes em semestres passados realizaram e, ao mesmo tempo, ilustrando os conceitos debatidos naquela aula.

Ao longo dos tempos, uma cena se mostrou comum: no início do semestre, os estudantes acham o projeto das dublagens muito divertido; ao final, com o trabalho entregue, não raro o comentário é: "professor, foi divertido, mas muito mais difícil do que eu pensava”. A dificuldade relatada pelos estudantes refere-se ao processo de tradução e ao próprio processo de comunicação, fazendo circular os sentidos entre o texto do teórico da comunicação e um vídeo advindo da cultura midiática, com os constrangimentos enquanto dispositivo comunicacional. Em geral, quando se cobra, como método de avaliação, os conhecimentos dos estudantes em relação a um texto específico, é comum a solicitação de resenhas, formato que os estudantes acabam por se acostumar. Então, há menos dificuldade 
na tradução do texto acadêmico visto em sala de aula para um outro texto acadêmico que o esforço de passagem para outros dispositivos comunicacionais.

Para realizar o vídeo de dublagem, preciso, primeiramente, escolher a(s) cena(s) a ser(em) dublada(s) e, a partir dela, produzir um roteiro que, ao mesmo tempo, encaixe nas falas das personagens e também explique as teorias que constam no texto. A partir do roteiro, é necessário que ele ganhe voz e se concretize no vídeo de dublagem. Surgem, ao longo do processo, alguns dilemas: qual cena escolher? Por que escolher tal cena? Quais palavras eu uso? Como fazer para, ao mesmo tempo, o roteiro fazer sentido teoricamente e também na própria "cena discursiva" 36 ? É necessário fazer humor a partir da dublagem?

A construção de um roteiro - a partir da passagem do texto e seu respectivo fichamento para o formato das falas a serem encenadas - é uma parte crucial da construção da dublagem enquanto dispositivo, de maneira que essa elaboração, ao longo dos semestres, foi sendo sistematicamente orientada pelo docente na disciplina. Os estudantes não são obrigados a eles mesmos emprestarem a voz aos personagens - em alguns casos, primos, amigos e irmãos são os dubladores. A remixagem é importante, mas ela não se basta em si mesma, precisando de um roteiro consistente em relação aos os conceitos e teorias. Ao longo dos anos, houve dublagens em que o trabalho com as vozes beirava à perfeição, mas o roteiro era incoerente com as teorias apresentados, o que se mostra impertinente à proposta.

Com o passar dos semestres, o processo pedagógico foi se aperfeiçoando. Logo de cara, a partir da experiência do vídeo anterior "Lazarsfeld apanha de Adorno", foram desencorajados vídeos que contivessem duelos ou brigas entre autores, tal qual na cena dublada da novela Celebridade. O papel da ciência não pode ser representado como lutas físicas entre pesquisadores. No mesmo sentido, depois de um trabalho apresentado em que o ator Chuck Norris representava Henry Jenkins - com frases como "Prazer, meu nome é Henry Jenkins" - também foram desencorajados roteiros em que o autor fosse o personagem da cena. Desta maneira, é possível evitar cair na caricatura do autor em si, pois o que importam são as explicações de suas ideias. Essas questões têm feito com que o processo educomunicativo em relação às dublagens esteja mais preocupado com a concatenação entre "plano do conteúdo" e "plano da expressão" "37, isto é, que, ao mesmo tempo, apresente um roteiro coerente às questões teórico-epistemológicas e que a cena escolhida também seja pensada de forma a observar como aquelas teorias serão representadas imageticamente. Em disciplina ministrada em 2018, os alunos já conseguiram problematizar em quais cenas seriam melhores para representar temas como "comunicação e questões raciais" ou "comunicação e gênero", por exemplo.

Outro desafio, ainda a ser enfrentado com mais ênfase, é a ânsia, por parte de estudantes, por transformarem os vídeos de dublagem em algo humorístico, com usos de memes no roteiro, por exemplo. Por um lado, como parte do processo de mediação/tradução ${ }^{38}$, os memes e o humor podem ser efeitos interessantes da dublagem como dispositivo educomunicativo, isto é, remixando teorias com memes - como mostram, por exemplo, os trabalhos de Viktor Chagas ${ }^{39}$ acerca

36. MAINGUENEAU, Dominique. Novas tendências em análise do discurso. Campinas: Ed. Pontes, 1997. 37. HJELMSLEV, Louis. op. cit., 1975. 
dos memes como possibilidade de letramento político e o humor facilitando a difusão dos conteúdos e essas experiências de letramento - ponto convergente com as dublagens como dispositivos educomunicativos. Contudo, não se pode encerrar esses vídeos nos memes, ou o humor pelo humor, como se bastassem por si mesmos, precisando convergir para epistemologizar a cultura pop, no sentido de uma crítica midiática.

Dentre os mais de 100 vídeos apresentados, alguns não foram publicados por conterem muitos erros, outros (por exemplo, "Toy Story explicam Adorno" e "Manuel Castells em Matrix") foram bloqueados no Youtube por direitos autorais, e outros publicados tanto no Youtube quanto no Facebook. A partir de 2018, o projeto teve uma pequena modificação: prevê que cada grupo de alunos leia um livro completo de um autor da bibliografia da disciplina e produza, ao menos, três vídeos de dublagem. Isso propicia aos alunos um contato maior com o autor e os conceitos e a oportunidade de produzir vídeos com conceitos mais bem explicados.

Por fim, gostaríamos de mencionar os vídeos com maior repercussão nas plataformas digitais até o momento de escrita do artigo, a saber: "Spice Girls explicam Foucault - Verdade \& Poder" (desenvolvido em 2016) e "Gandalf explica Bourdieu (desenvolvido em 2013). Os comentários nos vídeos variam desde elogios e reprodução de algumas falas dos vídeos até frases como "Coitado do Foucault se revirando no caixão" e outras visibilizando a questão da aprendizagem, como: "Eu aqui tentando resumir Foucault para um seminário e vocês me aparecem com essa paródia. Valeu"; "Parabéns, ficou muito bom, e aprendi muito!", "Professores usam esse vídeo demais em aula", "Amei... Sou professora de Sociologia da UFMG... achei muito bom!".

De maneira geral, os vídeos acima seguem alguns dos parâmetros discutidos acima acerca da dublagem como dispositivo educomunicativo, mas como qualquer tentativa, também é passível de debates, tais como: por que Foucault em um clipe das Spice Girls? Como a novela A Usurpadora ajuda em debates sobre Deleuze? O quanto isso ajuda ou não a atuar nas brechas? Questões como essas continuarão a surgir e serão levadas a discussão em salas de aula.

\section{CONSIDERAÇÕES FINAIS}

Em suma, o artigo se propôs a refletir sobre experiências educomunicativas no "chão de fábrica" das Teorias da Comunicação, a sala de aula, a partir de um objeto concreto, as dublagens produzidas por estudantes de graduação tomadas como dispositivos educomunicativos - considerando possibilidades,

38. SILVERSTONE, Roger. op. cit., 2002

39. CHAGAS, Viktor. A febre dos memes de política. Famecos, Porto Alegre, v. 25 n. 1,2018. limites e brechas, procurando compreender questões de práxis, circulação de sentidos, remix, e a própria comunicação/circulação das Teorias da Comunicação para além do campo acadêmico, com seus desafios e dilemas, combatendo a "illusio escolástica", em um movimento dialético de "epistemologizar a cultura pop" e "popularizar a epistemologia". 
Esse movimento se relaciona com as mudanças da comunicação científica e do trabalho acadêmico e suas interrelações com as mídias digitais. O que se coloca são possibilidades de circulação e comunicação da ciência para além dos formatos enquadrados como "propriamente acadêmicos". Em um contexto político em que o conhecimento produzido pelas universidades é questionado, é preciso haver um investimento coletivo em maneiras de popularizar a epistemologia, fazendo circular por outros circuitos os seus sentidos.

O artigo apresenta limites por se tratar de uma autorreflexão sobre práticas pedagógicas no ensino de teorias da comunicação e não um estudo de recepção sobre essas práticas ou análise de outros dispositivos educomunicativos, de maneira que não foi objetivo do texto criar indicadores sobre eficácia desta ou daquela prática. As vantagens das dublagens enquanto dispositivos educomunicativos são, principalmente, as possibilidades de reapropriação e circulação de sentidos. Suas limitações são um processo lento de crítica midiática no sentido de epistemologizar a cultura pop - para que não se reifique o conteúdo como "humor pelo humor" e as condições das materialidades/infraestruturas para circulação midiática..

Se, nos limites desse texto, apresentamos, de forma modesta, uma autorreflexão sobre práticas pedagógicas em teorias da comunicação, o que se propõe como mais relevante para a pesquisa em comunicação é justamente esse movimento dialético entre epistemologizar a cultura pop - que, por vezes, é atravessada por discursos com desconfiança - e popularizar a epistemologia, de maneira a combater um etnocentrismo escolástico e, ao mesmo tempo, manter acesa a chama do que Vieira Pinto ${ }^{40}$ denomina como "periculosidade social da ciência". Desta forma, esse movimento não se propõe como algo meramente "fofinho" ou "esvaziado de sentido". Pelo contrário, trata-se de, nos limites do próprio dispositivo, preenchê-lo de sentidos de atividade, ao mesmo tempo, epistemológica e política. Fazer circular teorias da comunicação é um esporte de combate.

\section{REFERÊNCIAS}

BACCEGA, Maria Aparecida. Do mundo editado à construção do mundo. Comunicação \& Educação, São Paulo, v. 1, n. 1, p. 8, 1994.

BOURDIEU, Pierre. Meditações pascalianas. Rio de Janeiro: Bertrand Brasil, 2001.

BUZATO, Marcelo. et al. Remix, mashup, paródia e companhia: por uma taxonomia multidimensional da trantextualidade na cultura digital. Revista Brasileira de Linguística Aplicada, Belo Horizonte, v. 13, n. 4, p. 1203, 2013.

CHAGAS, Viktor. A febre dos memes de política. Famecos, Porto Alegre, v. 25, n. 1,, 2018.

CITELLI, Adilson. Comunicação e educação: a linguagem em movimento. São Paulo: Ed. Senac, 2000 
CITELLI, Adilson; COSTA, Cristina (org.). Educomunicação: construindo uma nova área de conhecimento. São Paulo: Paulinas, 2011

DALMONTE, Edson. Novos cenários comunicacionais no contexto das mídias interativas: o espalhamento midiático. Famecos, Porto Alegre, v. 2, n. 17, p. 105, 2015.

FERRAZ, Luiz Marcelo Robalinho. A modelização como ferramenta complementar no ensino de Teoria da Comunicação. Comunicação \& Educação, São Paulo, v. 23, n. 1, 2018.

FISCHER, Rosa Maria Bueno. O dispositivo pedagógico da mídia: modos de educar na (e pela) TV. Educação e Pesquisa, São Paulo, v. 28, n. 1, p. 151-162, 2002.

FREIRE, Paulo. Extensão ou comunicação?. Rio de Janeiro: Paz e Terra, 1985.

GENETTE, Gérard. Seuls. Paris: Éditions du Seuil, 1987.

HJELMSLEV, Louis. Prolegômenos a uma teoria da linguagem. São Paulo: Perspectiva, 1975.

KELLNER, Douglas; KIM, Gooyong. YouTube, critical pedagogy, and media activism. The Review of Education, Pedagogy, and Cultural Studies, Abingdon, v. 32, n. 1, p. 3-36, 2010

LEMOS, André. Ciber-cultura-remix. Apresentação proferida na mesa "Redes: criação e reconfiguração", do Seminário "Sentidos e Processos". São Paulo: Itaú Cultural, 2005, p. 5.

MAINGUENEAU, Dominique. Análise de textos de comunicação. São Paulo: Cortez, 2001.

MAINGUENEAU, Dominique. Novas tendências em análise do discurso. Campinas: Ed. Pontes, 1997.

MARTIN-BARBERO, Jesús. Dos meios às mediações. Rio de Janeiro: Ed. UFRJ, 1995.

MARTINI, Rafael. Educação e comunicação em ambiente associativo: web site como um dispositivo de educomunicação. 2009. Dissertação (Mestrado em Educação) - Universidade do Estado de Santa Catarina, 2009.

MARTINO, Luís Mauro Sá. A disciplinarização da Epistemologia no ensino da (s) Teoria (s) da Comunicação. Intexto, Porto Alegre, n. 29, p. 1-17, 2013.

NAVAS, Eduardo. Regressive and reflexive mashups in sampling culture. In: SONVILLA-WEISS, Stefan (org.). Mashup cultures. New York: Springer, 2010. p. 157-177.

OLIVEIRA, Thaiane. Midiatização da Ciência: reconfiguração do paradigma da comunicação científica e do trabalho acadêmico na era digital. MATRIZes, São Paulo, v. 12, n. 3, p. 103, 2018. 
PERAYA, Daniel. O ciberespaço: um dispositivo de comunicação e de formação midiatizada. In: ALAVA, Séraphin (org.) Ciberespaço e formações abertas: rumo a novas práticas educacionais?. Porto Alegre: Artmed, 2002. p. 25-52.

RUSSI-DUARTE, Pedro. Por que ensinar teoria (da comunicação)?. In: INTERCOM, 10., Caxias do Sul. Anais [...]. Caxias do Sul: UCS, 2010.

SILVERSTONE, Roger. Por que estudar a mídia?. São Paulo: Loyola, 2002. p. 35.

SOARES, Ismar de Oliveira. Gestão comunicativa e educação: caminhos da educomunicação. Comunicação \& Educação, São Paulo, n. 23, p. 24, 2002.

STREET, John. Politics and popular culture. London: Temple, 1997.

VIEIRA PINTO, Álvaro. Ciência e existência: problemas filosóficos da pesquisa científica. Rio de Janeiro: Paz e Terra, 1979.

WOODCOCK, Jamie. Marx at the arcade: consoles, controllers, and class struggle. London: Haymarket, 2019. 